\title{
Glycine betaine mediated disease resistance against Sclerospora graminicola in Pearl Millet
}

\author{
Nagaraju S. Lavanya, Nagaraj K. Amruthesh* \\ Applied Plant Pathology Laboratory, Department of Studies in Botany, University of Mysore, Mysuru-06, Karnataka, India.
}

\begin{tabular}{|c|c|}
\hline ARTICLE INFO & ABSTRACT \\
\hline $\begin{array}{l}\text { Article history: } \\
\text { Received on: } 28 / 10 / 2016 \\
\text { Accepted on: } 18 / 01 / 2017 \\
\text { Available online: } 19 / 06 / 2017\end{array}$ & $\begin{array}{l}\text { The present findings on Glycine betaine provides significant perception on the dynamics of pearl millet by } \\
\text { activating the host defense responses during its interaction with the pathogen. Glycine betaine treatment to seeds } \\
\text { at } 30 \mathrm{mg} \mathrm{ml}^{-1} \text { concentration for } 6 \mathrm{~h} \text { significantly enhanced the seed germination and seedling vigor of pearl millet } \\
\text { in comparison with the control. Significant inhibition of sporangial sporulation, zoospore release and motility was }\end{array}$ \\
\hline $\begin{array}{l}\text { Key words: } \\
\text { Glycine betaine, } \\
\text { Pearl millet, } \\
\text { Downy mildew, } \\
\text { Sprongiospores, } \\
\text { Hypersensitive reaction. }\end{array}$ & $\begin{array}{l}\text { observed at } 30 \mathrm{mg} \mathrm{ml} \text {, even though it falled to exhibit complete nhibition in all the concentrations tested. TTC } \\
\text { assay confirmed the declined release of sporangiospores from sporangia by inhibiting the viability of } \\
\text { sporangiospores. Inducer treated seedlings recorded an early and increased hypersensitive response as a reaction } \\
\text { to Sclerospora graminicola inoculation compared to untreated. The effect of Glycine betaine was tested by seed } \\
\text { treatment alone, seed treatment + foliar application and foliar application alone. Significant inhibition of disease } \\
\text { control was noticed in seed treatment followed by foliar application with } 19.2 \% \text { disease incidence at } 30 \mathrm{mg} \mathrm{ml}^{-1} \text {. } \\
\text { Spatio-temporal studies indicated that seed treatment with Glycine betaine increased disease protection three days } \\
\text { after inoculation. With these results, Glycine betaine has been shown to be an effective compound for the control } \\
\text { of downy mildew disease in pearl millet. }\end{array}$ \\
\hline
\end{tabular}

\section{INTRODUCTION}

Plants have evolved different strategies to retain water under unfavorable environmental conditions through the wellknown protective mechanisms by the accumulation of compatible solutes such as polyols, sugars, amino acids, betaine. Glycine betaine (GB) N,N,N-trimethyl-glycine is an amino acid derivative naturally synthesized and accumulated in response to variety of abiotic stress conditions by numerous organisms including bacteria, cyanobacteria, algae, fungi, animals and in plant families [1]. Highest amount of GB is present in storage roots of sugar beet in epicotyl and hypocotyl tissues [2]. GB is one of the most studied compatible compound for abiotic stress tolerance due to its versatile function. Several studies have shown that level of GB is increased in naturally accumulating plants under stressful conditions [3]. It also protects plants against various stresses and also protects quaternary structure of proteins, various enzymes and other macromolecules involved in disease protection [4].

\footnotetext{
* Corresponding Author

Amrurhesh K Nagaraj, Applied Plant Pathology Laboratory Department of Studies in Botany University of Mysore Mysuru-06, India.

Email dr.knamruthesh @ botany.uni-mysore.ac.in
}

Genetically engineered GB producing plants have shown increased tolerance to a wide variety of environmental stress including drought, salinity, low and high temperatures, and oxidative damage [5]. It has been shown to protect higher plants against salt/osmotic stress by playing an osmolyte role [6] and protecting the photosystem II (PSII) complex under salinity [7], extreme temperature and $\mathrm{pH}$ [8]. In higher plants, $\mathrm{GB}$ is synthesized from choline by two-step oxidation reactions that are catalyzed by choline monooxygenase (CMO) and betaine aldehyde dehydrogenase (BADH) respectively [9]. Beside, a biosynthetic pathway of GB from glycine by the activity of two $\mathrm{N}$-methyl transferase enzymes has recently been reported [10].

Pearl millet (Pennisetum glaucum (L.) R. Br.) is an important grain and poor man's staple crop grown in arid and semi-arid tropical regions of Asia, Africa and Latin America. India is the largest producer of pearl millet with an annual production of about 9.25 million tones grown on 7.8 million hectares [11]. In most of the regions, pearl millet is predicted as a climate change amenable crop. It is a rich source of energy, protein, vitamins and minerals. Beneficial properties of pearl millet in terms of nutrition play a vital role in securing food for poorest of the poor [12]. Pearl millet is very much prone to many diseases such as downy mildew, rust, smut, ergot and blast. 
Downy mildew of pearl millet is caused by the biotrophic, oomycete Sclerospora graminicola (Sacc.) Schroet and is the most widespread disease with continuing potential to cause catastrophic loss.

Estimated average annual yield losses can reach up to $40 \%$ annually worldwide and it can reach nearly $100 \%$ in farmer's field where susceptible cultivar is grown repeatedly [13]. Efforts to control the disease by the usage of fungicides are found to be effective in reducing the level of disease incidence, but have a contrary influence on environment [14]. The ability of the pathogen to progress and escape from resistance mechanism has directed the researchers to develop many alternative protection approaches. Priming of seeds with biotic and abiotic elicitors is one among them.

The use of chemicals targeted against oomycetes provides some level of disease control, however, in the long term the development of crops that possess tough innate resistance whether by classical breeding methods or by genetic engineering provides the best prospect for effective, economical and ecofriendly approach to the control of diseases [15].

The present work was carried out to evaluate the efficacy of GB in effective control of downy mildew incidence in pearl millet under laboratory and greenhouse conditions.

\section{MATERIALS AND METHODS}

\subsection{Host and Pathogen}

Pearl millet seeds cv. highly susceptible (7042S) and highly resistant (IP18292) to downy mildew pathogen $S$. graminicola, obtained from All India Coordinated Research Project on Pearl Millet (AICRP-PM), Mandor, Rajasthan, India, were used throughout the experimental studies.

$S$. graminicola collected from heavily infected leaves of twenty-one day old susceptible cultivar grown in the sick plot were used as source of inoculum throughout the study. Leaves of pearl millet showing profuse sporulation were collected in the evening, leaves were thoroughly washed under running tap water to remove existing sporangia and were blot dried, kept overnight for sporulation [16]. In the following morning, fresh crop of sporangia were harvested and the spore load was adjusted to 40,000 zoospore $\mathrm{ml}^{-1}$ using a haemocytometer.

\subsection{Preparation of Inducer and Seed Treatment}

Glycine betaine were obtained from Sisco Research Laboratories Pvt. Ltd. Mumbai and were prepared at different concentrations of 10,20,30,40 and $50 \mathrm{mg} \mathrm{ml}^{-1}$ in sterile distilled water and mixed on a stirrer for a few minutes to ensure complete solubalization or until no granules were left over.

Pearl millet susceptible seeds were treated by soaking in 10, 20, 30, 40 and $50 \mathrm{mg} \mathrm{ml}^{-1}$ concentrations of GB for 3 and $6 \mathrm{~h}$ at $25 \pm 2{ }^{\circ} \mathrm{C}$ with constant shaking on a rotary shaker and were air dried aseptically. Seeds soaked in sterile distilled water for the same period of time served as control.

\subsection{Effect of GB treatment on seed germination and seedling vigor}

Treated and control seeds were subjected to a germination test by the paper towel method [17]. Percentage germination and vigor index were calculated after seven days [18]. Four replicates of 100 seeds were used for each treatment and were repeated thrice. The concentrations and time interval which did not have any inhibitory effect on seed germination and seedling vigor were used for further experimental studies.

\subsection{Effect of different concentrations of GB on Sclerospora graminicola sporangial formation, zoospore release and its motility}

Downy mildew infected leaves of susceptible cultivar (7042S) were collected from greenhouse. The leaves were thoroughly washed in running tap water to remove the existing sporangia. Leaves were then blotted dry, cut into small pieces of $1 \mathrm{~cm} \mathrm{x} \mathrm{cm}$ size and subsequently treated with different concentration of GB solution for 30 mins. Distilled water treated leaves served as control. The leaf pieces were blot dried and placed in a moist chamber over night for sporulation. The next morning, each leaf piece was examined for the numbers of sporangia in five different microscopic fields were counted and tabulated. On the other hand, percentage of sporangia releasing zoospores and motility of zoospores were counted in all the above tested concentrations compared to control.

\subsection{Effect of GB on Sporangiosporicidal Assay}

Sporangiosporicidal Assay was assayed according to the procedure of [19] with slight modifications. Sporangial suspension was prepared as explained earlier, $100 \mu$ l of sporangial suspension and $100 \mu \mathrm{l}$ of different concentrations of GB were added with $20 \mu \mathrm{l}$ of Triphenyltetrazolium chloride (TTC) solution and incubated in a moist chamber for $1 \mathrm{~h}$. One set without inducer solution kept as control. After incubation, the mixture was centrifuged at $8000 \mathrm{rpm}$ for 8 mins and the pellet was washed twice with sterile distilled water. The pellet was again dissolved in $300 \mu$ l of sterile distilled water. The number of viable spores was calculated by counting number of colored sporangia with zoospores using hemocytometer. Suspension was again centrifuged and the pellet was mixed with $300 \mu$ of $95 \%$ ethanol and incubated in a water bath at $80^{\circ} \mathrm{C}$ for 20-30 min for quantification of formazane formed in cells. The mixture was further centrifuged at $8000 \mathrm{rpm}$ for 8 min. $100 \mu \mathrm{l}$ supernatant was transferred to a microtiter plate and read at $485 \mathrm{~nm}$ along with the control set. Assay was repeated thrice and readings were tabulated.

\subsection{Influence of GB on Hypersensitive reaction (HR)}

HR was studied in the test seedlings as described by [20]. Pearl millet seeds of highly susceptible (7042S), highly resistant (IP18292) and susceptible seeds treated for $6 \mathrm{~h}$ with different concentrations of GB were germinated on moist filter paper at $25 \pm 2{ }^{\circ} \mathrm{C}$ under aseptic conditions. 
Two-day old seedlings were inoculated with $40,000 \mathrm{ml}^{-1}$ zoospore suspension of $S$. graminicola. The pearl millet inoculated seedlings of were observed at different time intervals for a period of 0 to $24 \mathrm{~h}$ for the external appearance of necrotic spots or streaks on the coleoptile region. The initial time of appearance of HR and the total number of seedlings showing the necrotic spots during the trial period of $24 \mathrm{~h}$ was recorded and the percentage of seedlings showing HR were calculated. The experiment consisted of four replicates of 100 seedlings each and repeated thrice.

$$
\text { Percentage HR }=\frac{\text { No. of seedlings with Necrotic spots }}{\text { Total No. of seedlings }} \times 100
$$

\subsection{Estimation of different concentrations of GB for their potential to stimulate resistance against downy mildew under greenhouse conditions}

\subsubsection{Effect of GB on Seed treatment, Foliar spray and Seed treatment followed by foliar spray}

Seeds were treated with GB as described earlier. Treated seeds were sown to earthen pots containing soil: sand: manure (2:1:1) under greenhouse conditions. Two-day old seedlings were inoculated with zoospore suspension of $S$. graminicola following standard practices [21]. Seeds treated with sterile distilled water served as control and metaxyl formulation Apron 35SD at $6 \mathrm{~g} \mathrm{~kg}^{-1}$ concentration served as chemical control. Each treatment consisted of 25 plants in four replications and repeated thrice. Disease incidence was recorded at 30 and 60 days after sowing.

One set of untreated seeds were sown and inoculated as described earlier. Different concentrations of GB were foliarsprayed continuously for three days using a portable hand sprayer until run off. Plants were maintained and observed daily for the expression of the disease under greenhouse conditions.

Another set of treated seeds were sown and inoculated as explained before. Treated seedlings were foliar sprayed with different concentration of GB continuously for three days using a portable hand sprayer until run off. Plants were maintained and perceived daily for the disease symptoms under greenhouse conditions.

\subsubsection{Evaluation of GB on Stability of disease resistance}

Seeds treated for $6 \mathrm{~h}$ with concentration of $30 \mathrm{mg} \mathrm{ml}^{-1}$ were sown to earthenware pots filled with 2:1:1 ratio of soil, sand and manure. Emerging seedlings were inoculated with zoospore suspension of $S$. graminicola by whorl inoculation to each plant and maintaining the time gap of 1, 2, 3, 4 and 5 days between treatment and inoculation. Plants were maintained under greenhouse conditions and downy mildew disease incidence was recorded at 30 and 60 days. Each treatment consisted of 25 plants in four replicates and repeated thrice.

In another set, seedlings raised from susceptible pearl millet seeds were grown on moist blotter for $48 \mathrm{~h}$ at $25 \pm 2^{\circ} \mathrm{C}$. After $48 \mathrm{~h}$, seedlings roots were treated with inducer for same interval of time. Seedlings were then transplanted into earthen pots and maintained under greenhouse conditions. Seedlings were whorl inoculated as explained earlier and was maintained the time interval of 1, 2, 3, 4 and 5 days between treatment and inoculation. Plants were observed daily for the expression of downy mildew symptom.

\section{STATISTICAL ANALYSIS}

Data were analyzed separately for each experiment and subjected to arcsine transformation and analysis of variance (ANOVA) using SPSS Inc. 16.0. Significant effects of treatments were determined by magnitude of $F$ values $(P \leq 0.05)$. Treatment means were separated by Tukey's HSD test.

\section{RESULTS}

\section{1. Effect of GB treatment on seed germination and seedling vigor}

The seeds treated with different concentration exhibited enhanced seed germination and seedling vigor over the control at 6 $\mathrm{h}$ when compared to $3 \mathrm{~h}$ (Tab.1). Seed treatment with GB concentration of $30 \mathrm{mg} \mathrm{ml}^{-1}$ at $6 \mathrm{~h}$ time interval was found to be highest with $97 \%$ germination and 1767 seedling vigor and was selected for further experiments. The control seeds recorded $83 \%$ germination and seedling vigor of 1250 .

Table 1: Effect of GB seed treatment on seed germination and seedling and seedlings vigor under laboratory conditions.

\begin{tabular}{lcccc}
\hline $\begin{array}{l}\text { Concentration } \\
\left.\mathbf{m g ~ m l}^{\mathbf{1}}\right)\end{array}$ & \multicolumn{2}{c}{ Percentage Germination } & \multicolumn{2}{c}{ Seedling Vigor } \\
\cline { 2 - 5 } & $\mathbf{3 h}$ & $\mathbf{6 h}$ & $\mathbf{3 h}$ & $\mathbf{6 h}$ \\
\hline 10 & $83.7 \pm 0.3^{\mathrm{ab}}$ & $90.3 \pm 0.4^{\mathrm{b}}$ & $1252.0 \pm 22.3^{\mathrm{ab}}$ & $1343.3 \pm 10.1^{\mathrm{b}}$ \\
20 & $85.2 \pm 0.5^{\mathrm{bc}}$ & $92.9 \pm 0.8^{\mathrm{c}}$ & $1359.3 \pm 43.5^{\mathrm{bc}}$ & $1410.7 \pm 8.1^{\mathrm{c}}$ \\
30 & $91.6 \pm 0.5^{\mathrm{d}}$ & $97.0 \pm 0.4^{\mathrm{e}}$ & $1563.7 \pm 58.8^{\mathrm{d}}$ & $1767.0 \pm 8.1^{\mathrm{e}}$ \\
40 & $87.4 \pm 0.6^{\mathrm{c}}$ & $96.1 \pm 0.3^{\mathrm{de}}$ & $1420.7 \pm 7.8^{\mathrm{cd}}$ & $1561.3 \pm 14.9^{\mathrm{d}}$ \\
50 & $84.8 \pm 0.5^{\mathrm{ab}}$ & $94.2 \pm 0.4^{\mathrm{cd}}$ & $1282.0 \pm 31.3^{\mathrm{abc}}$ & $1456.3 \pm 6.9^{\mathrm{c}}$ \\
Control & $82.6 \pm 0.3^{\mathrm{a}}$ & $82.7 \pm 0.4^{\mathrm{a}}$ & $1155.3 \pm 13.5^{\mathrm{a}}$ & $1249.7 \pm 18.4^{\mathrm{a}}$ \\
\hline
\end{tabular}

Means followed by same letters are not significantly different from each other, as indicated by tukey's HSD test $(\mathrm{P} \leq 0.05)$.

\subsection{Effect of different concentrations of GB on Sclerospora graminicola sporangial formation and zoospore release and its motility \\ Inhibition of sporulation was noticed in all GB} concentrations compared to control. As the concentration increase inhibition of sporangial number and zoospore release is inhibited in all treatments compared to untreated. All the above tested concentrations failed to inhibit zoospore release completely. With concentration of $30 \mathrm{mg} \mathrm{ml}^{-1}$ perceived maximum inhibition of sporulation to 369 sporangia $\mathrm{cm}^{-2}$, whereas the untreated control recorded 15550 sporangia $\mathrm{cm}^{-2}$. All the tested concentration proved to be effective in inhibiting zoospore release and arresting zoospore motility.

Though, leaves treated with $30 \mathrm{mg} \mathrm{ml}^{-1}$ recorded maximum inhibition in zoospore release and motility compared to all other concentrations significantly. Determined inhibition of 
zoospore release was recorded at $30 \mathrm{mg} \mathrm{ml}^{-1}$ followed by $40 \mathrm{mg}$ $\mathrm{ml}^{-1}$ with zoospore release of $5.2 \%$ and $11.8 \%$ and motility of $2.4 \%$ and $9.4 \%$ respectively (Tab.2).

Table 2: Effect of different concentration of GB on Sclerospora graminicola sporangial formation, zoospore release and its motility.

\begin{tabular}{cccc}
\hline $\begin{array}{c}\text { Concentration } \\
\left(\mathbf{m g ~ m}^{-1}\right)\end{array}$ & $\begin{array}{c}\text { No. of Sporangia } \\
\mathbf{c m}^{-2}\end{array}$ & $\begin{array}{c}\text { Sporangia } \\
\text { releasing } \\
\text { Zoospores (\%) }\end{array}$ & $\begin{array}{c}\text { Zoospores } \\
\text { showing } \\
\text { motility (\%) }\end{array}$ \\
\hline 10 & $9580( \pm 281.6)^{\mathrm{e}}$ & $45.5( \pm 0.6)^{\mathrm{e}}$ & $36.8( \pm 0.2)^{\mathrm{d}}$ \\
20 & $8250( \pm 104.1)^{\mathrm{d}}$ & $17.5( \pm 0.3)^{\mathrm{c}}$ & $22.6( \pm 0.5)^{\mathrm{c}}$ \\
30 & $369( \pm 29.7)^{\mathrm{a}}$ & $5.2( \pm 0.2)^{\mathrm{a}}$ & $2.4( \pm 0.1)^{\mathrm{a}}$ \\
40 & $2500( \pm 157.2)^{\mathrm{b}}$ & $11.8( \pm 0.3)^{\mathrm{b}}$ & $9.4( \pm 0.3)^{\mathrm{b}}$ \\
50 & $5467( \pm 186.2)^{\mathrm{c}}$ & $21.1( \pm 0.3)^{\mathrm{d}}$ & $17.5( \pm 0.3)^{\mathrm{c}}$ \\
Control & $15550( \pm 298.6)^{\mathrm{f}}$ & $90.2( \pm 0.1)^{\mathrm{f}}$ & $100( \pm 0)^{\mathrm{e}}$ \\
\hline
\end{tabular}

Means followed by different letters are significantly different from each other, as indicated by Tukey's HSD test $(\mathrm{P} \leq 0.05)$.

\subsection{Effect of different concentrations of GB on Sporangiosporicidal Assay}

The influence of GB on the viability of $S$. graminicola sporangia was determined by TTC test. GB treatment significantly inhibited the release of sporagiospores at $30 \mathrm{mg} \mathrm{ml}^{-1}$ concentration followed by $40 \mathrm{mg} \mathrm{ml}^{-1}$ with the OD of 0.32 and 0.5 respectively. There was also decline in viability of spores was observed in 30 $\mathrm{mg}$ ml-1 with $28.3 \%$ in comparison with untreated. The percentage of viability of spores correlates with the results of sporangiosporicidal activity. The result of TTC assay and viability of spores was tabulated in Fig. 1.

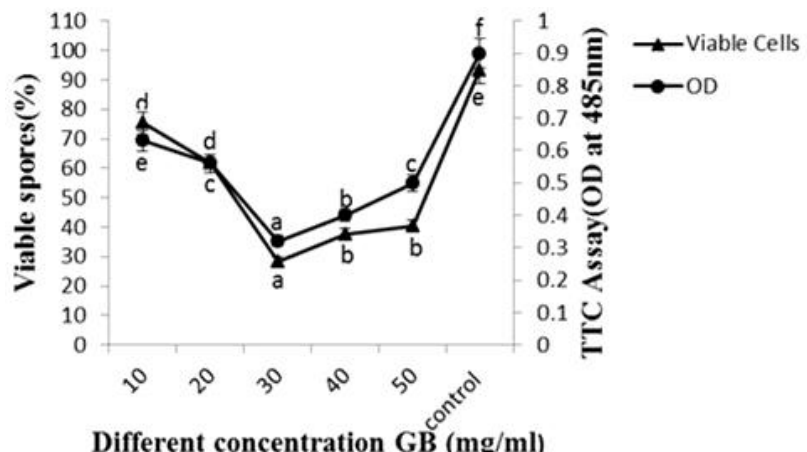

Fig. 1: Effect of different concentration of GB on Sporangiosporicidal activity. Bars indicate standard errors; means with same superscripts are not significantly different, as shown by Tukey's HSD test $(\mathrm{P} \leq 0.05)$.

\subsection{Influence of GB on Hypersensitive reaction (HR)}

Time course study of hypersensitivity reaction was conducted over a period of $24 \mathrm{~h}$ exhibited variable degree of responses in all tested seedlings at different time intervals after challenge inoculation with $S$. graminicola. HR was observed in the form of streaks or necrotic brown spots on tested seedlings. Streaks or number of necrotic spots was very prominent in resistant followed by induced resistant seedlings compared to highly susceptible seedlings.

In resistant seedlings, HR appeared as early as $2 \mathrm{~h}$ with $6 \%$ and by 12 and $24 \mathrm{~h}$ of time interval it was increased to $40 \%$ and $92 \%$ after inoculation respectively. Highly susceptible cultivar recorded only at $8 \mathrm{~h}$ after inoculation and reached the maximum of
$23 \% \mathrm{HR}$ at $24 \mathrm{~h}$. While with the GB treated seedlings, highest percentage of $\mathrm{HR}$ was recorded at $30 \mathrm{mg} \mathrm{ml}^{-1}$ compared to other concentrations and appeared initially at $2 \mathrm{~h}$ and it was raised maximum of $31 \%$ and $79 \%$ at 12 and $24 \mathrm{~h}$ after inoculation significantly (Fig.2). 10, 20, 40 and $50 \mathrm{mg} \mathrm{ml}^{-1}$ also exhibited increase in percentage of HR compared to susceptible inoculated seedlings.

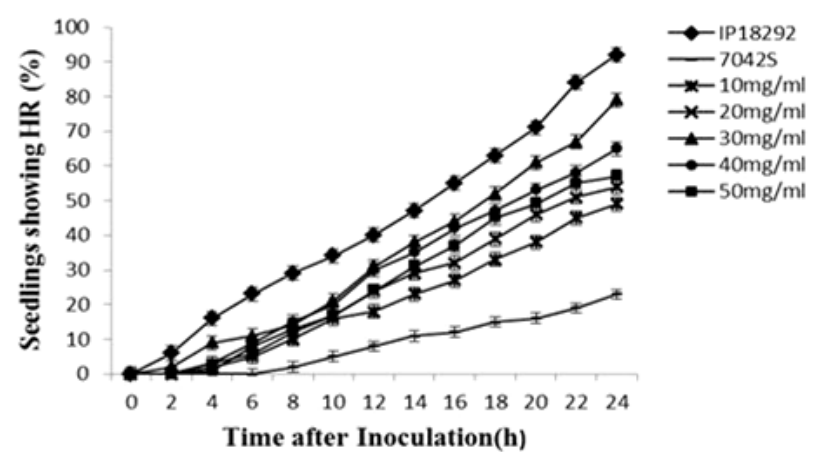

Fig. 2: Activity of different concentration of GB on Hypersensitive Reaction. Bars indicate standard errors.

\subsection{Estimation of different concentrations of GB treatment for their potential to stimulate resistance against downy mildew under greenhouse conditions}

\subsubsection{Effect of GB on Seed treatment, Foliar spray and Seed treatment followed by foliar spray}

The level of disease incidence varied with the different concentration of GB tested (Fig.3). Seed treatment revealed highest inhibition at $30 \mathrm{mg} \mathrm{ml}^{-1}$ with $33 \%$ of disease incidence. Apron 35SD used as standard control with least incidence of $16.6 \%$. However, there was a significant reduction in disease prevalence in all the test samples over the control with $94.6 \%$. Untreated plants with foliar spray recorded $41.3 \%$ of disease incidence compared to control. Significant inhibition of disease control was noticed in seed treatment followed by foliar spray with $19.2 \%$ at $30 \mathrm{mg} \mathrm{ml}^{-1}$ followed by $28.9 \%$ at $40 \mathrm{mg} \mathrm{ml}^{-1}$. Disease incidence of $46.0,39.7$ and $42.5 \%$ was obtained with 10,20 and $50 \mathrm{mg} \mathrm{ml}^{-1}$ respectively. However, $12.5 \%$ of disease incidence was evident in seed treatment followed by foliar spray with Apron 35SD was superior compared to all treatments in protecting plants against downy mildew.

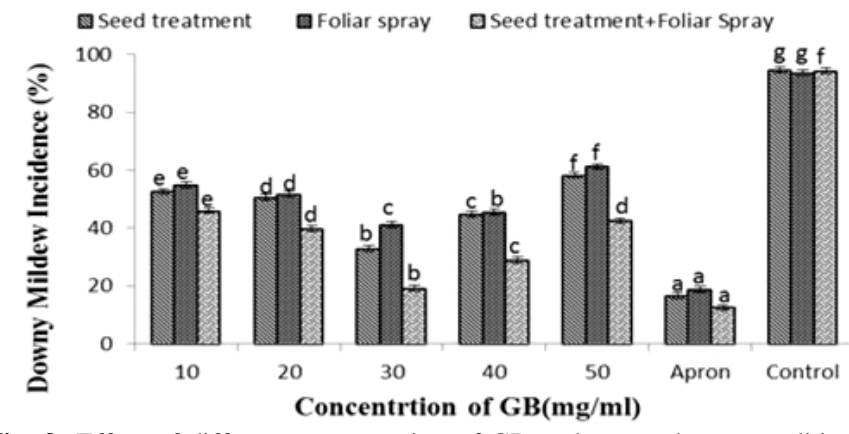

Fig. 3: Effect of different concentration of GB under greenhouse conditions. Bars indicate standard errors; means with same superscripts are not significantly different, as shown by Tukey's HSD test $(\mathrm{P} \leq 0.05)$. 


\subsubsection{Evaluation of GB on Stability of disease resistance}

With the above study, the resistance was found to be systemic when the GB offered the maximum protection was tested further by following spatio and temporal separation studies. In the first day, the GB treated plants recorded $41.3 \%$ protection when the time gap between seed treatment and inoculation were maintained (Fig. 4). For the second day, 54\% Protection was observed and it was raised to $71.5 \%$ for the third day. Minimum of three days was required to build up the resistance and it was maintained throughout the study.

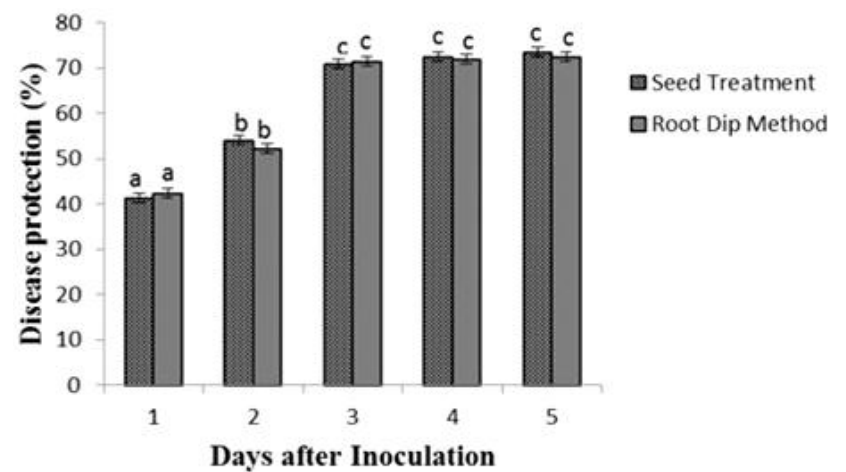

Fig. 4: Effect of GB on Spatio-Temporal studies under greenhouse conditions. Bars indicate standard errors; means with same superscripts are not significantly different, as shown by Tukey's HSD test $(\mathrm{P} \leq 0.05)$.

The inducer treatment to the root region resulted in comparable effects to seed treatment. At the first day, the protection offered was $42.3 \%$ and it was gradually increased to $52.3 \%$ and $71.5 \%$ for the second and third day interval respectively. The protection was found to be stable after third day and resistance induction was maintained at the same level.

\section{DISCUSSION}

Seed priming with biotic inducer offers many advantages over other delivery methods and reported to alleviate physiological and pathological stress by enlistment, initiation and development of various cellular defense responses [22]. Plants encounters with a variety of external factors; biotic (insect herbivores and microbial pathogens) and abiotic (extreme temperature, inappropriate water supply, etc.) stress adversely affect the growth and development. The various defense strategies against environmental stress and the involvement of well-known genes and signaling pathways could play a common role for triggering the abiotic and biotic stress responses.

GB is an amphoteric, electrically neutral, having three methyl groups at non-polar hydrocarbon moiety, with a wide range of physiological $\mathrm{pH}$ and solubility in water [23]. GB also involved in alleviating the structures, enzymes activity and protein complexes by maintaining the membranes integrity against the destructive effects of excessive salt, cold, heat and freezing [24].

The efficacy of seed treatment or foliar application of GB in improving drought resistance has been reported in different crops such as maize, tobacco, soybean and wheat [25]. Foliar spray of GB increased accumulation of phenolic compounds imparting efficiency in protecting strawberry plants has been reported by [26]. Similarly it also protects wheat plants against downy mildew signifies its promising role in plant protection against pathogens. Exogenously application of GB and HA(Humic acid) on drought-stressed Malus robusta seedlings unveil increased total dry matter, net photosynthetic rate, free proline content, endogenous glycine betaine content, soluble sugar content as well as the involvement in anti-oxidative enzymes activities of superoxide dismutase, peroxidase, and catalase [27].

The present study was targeted to know the ability of GB at different concentration to induce resistance against downy mildew in pearl millet. The results revealed the efficacy of GB with maximum seed germination and increased vigor at optimum concentration of $30 \mathrm{mg} \mathrm{ml}^{-1}$ at $6 \mathrm{~h}$ compared to $3 \mathrm{~h}$ of seed treatment. A similar pattern of concentration dependent treatment were reported in pearl millet seed treatment with 2, 3, 4, tri-iodo benzoic acid exhibited increase in seed germination and vigor [28].

GB solution exhibited high inhibition of zoospore release and its motility of $S$. graminicola during in-vitro studies. Inhibition of zoospore motility was significantly superior to that of zoospore release at the same concentration. Consistent results were found with the experiments carried out on Sclerospora graminicola suspension treated with six unsaturated fatty acids which are the effective inhibitors of sporangial formation and zoospore release when applied in optimal concentration [29].

Further, anti-mildew activity of GB was tested by sporangiosporicidal assay and percentage of viable spores. TTC assay indicates the presence of anti-mildew compound in GB that arrests the sporangial activity. Significantly inhibition of activity was observed at $30 \mathrm{mg} \mathrm{ml}^{-1}$ followed by $40 \mathrm{mg} \mathrm{ml}^{-1}$. Percentage of viability of cells exposed the similar effects to that of sporangicidal activity compared to control. Comparable results were found with partially purified anti-mildew compounds from M. citrifolia, Z. officinale and T. cordifollia significantly inhibited the release and viability of sporangiospores against Plasmopara halstedii in Sunflower [30].

In Pearl millet, several studies relating to host resistance mechanism were carried out by earlier workers. Rapid and confined death of a plant cells at the site of pathogen penetration is the early macroscopic indication of HR. HR was conducted over a period of $24 \mathrm{~h}$ after inoculation exposed differences in rapidity and percentage of seedlings showing HR in different test seedlings. In the present study, intensity of expression of HR is high in highly resistant and induced resistant seedlings and delayed expression was observed in susceptible. This is due to the restricted pathogen development in the area of penetration resulted in the resistant response to downy mildew. The early expression of HR indicates that induced resistance seedlings were sensitize by seed treatment with $30 \mathrm{mg} \mathrm{ml}^{-1}$ of GB compared to other concentrations. Above results are in pact with earlier reports against downy mildew in pearl millet which shows the association of HR with resistance 
response by benzothiadiazole, calcium chloride and hydrogen peroxide treatments [31].

Downy mildew caused by $S$. graminicola is most caustic disease of pearl millet. There was no complete inhibition of disease in all the treatments tested. Seed treatment using different concentration of GB affords significant disease control of 33\% over untreated plants. It is emphasized that foliar treatment alone was also evident in controlling the disease and exhibited similar reaction to that with seed treatment. On the other hand, seed treatment along with foliar application offered highest defensive activity with $19.2 \%$ at $30 \mathrm{mg} \mathrm{ml}^{-1}$, notably inhibited the disease progression. Similar results correlate with the earlier reports [32] in pearl millet on chitosan formulation Elexa ${ }^{\mathrm{TM}}$ which was used as seed treatment and foliar spray was effective in controlling downy mildew disease under greenhouse conditions. Systemic nature of induced and durability of resistance was evident with a minimum of three days of time interval required to build up maximum resistance in seed as well as root treatment after challenge inoculation with the pathogen. The assessment revealed that protection offered by GB was systemic and durable in nature. The induction of resistance has been reported in pearl millet against $S$. graminicola with proline treatment [33], where maximum protection was observed after three days of treatment.

In tomato plants, foliar application of GB improved chilling tolerance in tomato plants to provide sufficient protection against low temperature [34]. Since GB offered a new prospect to stabilize crop production under field conditions by increasing rate of photosynthesis, fruit yield of tomato plants grown in saline soils or exposed to high temperature as reported by [35]. Exogenous application of GB in soybean (Glycine max L.) enhanced salt tolerance supporting enzymes involved in protecting mechanism [36]. The role of GB in cold stress responses and indicated that GB role in inducing FAD7 and LOX expressions for providing protection against cold stress in tomato plants which could lead to desaturation of lipid peroxidation products by increasing membrane stability and genes involved in stress defense mechanism via octadecanoid pathway [37].

Thus, GB shown to be a versatile non-phytotoxic compound for the management of downy mildew disease in pearl millet by activating host defense responses. It was extensively studied as compatible compound for improving abiotic stress tolerance, here it has undertaken to upsurge present knowledge on resistance induction as seed or as foliar treatment in pearl millet. Experiments with GB, mainly studied as a natural compound for inducing disease resistance against downy mildew and aim of exploration on induced resistance is to control disease in practical and commercial situations.

\section{CONCLUSION}

GB treatment can also be preferred for pearl millet disease over other methods of application in commercial use. Although, this is a preliminary report on induction of resistance in pearl millet system. Exogenous application of GB is well studied as compatible compound for abiotic stress tolerance from past few decades. However, the use of natural inducer like GB might contribute as an aim towards sustainable agriculture and validation of application for disease management approach. Inducer application as described in this study suggests an easy, rapid and opportune for obtaining maximum protection against disease. With this study, this could be attributed to expose the role in induction of resistance against oomycete.

\section{ACKNOWLEDGEMENT}

Financial support and sponsorship: The facilities provided by the Indian Council of Agricultural Research (ICAR), Government of India, through All India Coordinated Research Project on Pearl Millet (AICRP-PM) are gratefully acknowledged.

Conflict of Interests: There are no conflicts of interest.

\section{REFERENCES}

1. Rhodes D, Hanson AD. Quaternary ammonium and tertiary sulfonium compounds in higher plants. Annual Review of Plant Physiology and Plant Molecular Biology. 1993; 44: 357384.

2. Beringer $\mathrm{H}$, Koch $\mathrm{K}$, Lindhauer MG. Sucrose accumulation and osmotic potentials in sugar beet at increasing levels of potassium nutrition. Journal of the Science of Food and Agriculture. 1986; 37: 211-218.

3. Chen TH, Murata N. Glycinebetaine protects plants against abiotic stress: mechanisms and biotechnological applications. Plant, Cell and Environment. 2011; 34: 1-20.

4. Papageorgiou GC, Murata N. The unusually strong stabilizing effects of glycine betaine on the structure and function of the oxygenevolving Photosystem II complex. Photosynthesis Research. 1995; 44: 243-252.

5. Chen THH, Murata N. Glycinebetaine: an effective protectant against abiotic stress in plants. Trends in PlantScience. 2008; 13: 499-505.

6. Jagendorf AT, Takabe T. Inducers of glycinebetaine synthesis in barley. Plant Physiology. 2001; 127(4): 1827-35.

7. Murata N, Mohanty PS, Hayashi H, Papageorgiou GC. Glycinebetaine stabilizes the association of extrinsic proteins with the photosynthetic oxygen-evolving complex. FEBS Letters. 1992; 296: 187-189.

8. Mohanty PS, Hayashi H, Papageorgiou GC, Murata N. Stabilization of the Mn-cluster of the oxygen-evolving complex by glycinebetaine. Biochimica et Biophysica Acta. 1993; 1144: 92-96.

9. Russell BL, Rathinasabapathi B, Hanson AD. Osmotic stress induces expression of choline monooxygenase in sugar beet and amaranth. Plant Physiology. 1998; 116: 859-865.

10. Waditee R, Bhuiyan MNH, Rai V. Genes for direct methylation of glycine provide high levels of glycinebetaine and abiotic-stress tolerance in Synechococcus and Arabidopsis. Proceedings of the National Academy of Sciences of the United States of America. 2005; 102: 1318-1323.

11. Pearl Millet News, March 2016. http//www.aicpmip.res.in

12. Deepak S, NiranjanRaj S, Lavanya SN, Mithofer Axel, Shekar Shetty H. Nutritional Bio-fortification in Pearl Millet. The European Journal of Plant Science and Biotechnology. 2012; 6.

13. Thakur RP, Sharma Rajan, Rao VP. Screening Techniques for Pearl Millet Diseases. International Crops Research Institute for the SemiArid Tropics. 2011; Information Bulletin No. 89: 56.

14. Sudisha J, Shigeru M, Amruthesh KN, Shekar Shetty H. Activity of cyazofamid against Sclerospora graminicola, a downy mildew disease of pearl millet. Pest Management Science. 2007; 63: 722-727. 
15. Sophien Kamoun, Edgar Huitema, Vivianne GAA, Vleeshouwers. Resistance to oomycetes: a general role for the hypersensitive responses? Trends in plants science. 1999; 4: 196-200.

16. Safeeulla KM. Biology and control of the downy mildews of pearl millet, sorghum and finger millet. Wesley Press, Mysore, India. 1976.

17. ISTA. International Rules for Seed Testing. International Seed Testing Association (Chapter V). 2003.

18. Abdulbaki AA, Anderson JD. Vigour determination in soybean seed by multiple criteria. Crop Science. 1974; 13: 630-633.

19. Maness PC, Smolinski S, Blake DM, Huang Z, Wolfrum EJ, Jacoby WA. Bactericidal activity of photocatalytic $\mathrm{TiO} 2$ reaction: toward an understanding of its killing mechanism. Applied and Environmental Microbiology.1999; 65(9): 4094-4098.

20. Kumudini BS, Vasanthi NS, Shetty H S. Hypersensitive response, Cell death and histochemical localization of hydrogenperoxide in host and non-host seedlings infected with the downy mildew pathogen Sclerospora graminicola. Annals of Applied Biology. 2001; 139: 217-225.

21. Singh SD, Gopinath RA. Seedling inoculation technique for detecting downy mildew resistance in pearl millet. Plant Disease. 1985; 72: 425-428.

22. Cornath U, Thulke O, Katz V, Schmindling S, Kohler A. Priming as a mechanism in induced systemic resistance of plants. European Journal of Plant Pathology. 2002; 107: 113-119.

23. Sakamoto A, Murata N. The role of glycine betaine in the protection of plants from stress: clues from transgenic plants. Plant, Cell and Environment. 2002; 25: 163-171.

24. Gorham J. Betaines in higher plants - biosynthesis and role in stress metabolism. In Amino Acids and Their Derivatives in Higher Plants (ed. R.M. Wallsgrove), Cambridge University Press, Cambridge. 1995: 171-203.

25. Ashraf M, Foolad MR. Roles of glycinebetaine and proline in improving plant abiotic stress resistance. Environmental and Experimental Botany. 2007; 59: 206-216.

26. Karjalainen R, Lehtinen A, Hietaniemi V, Pihlava JM, Jokinen K, Keinanen M, Julkunen-Tiito R. Benzathiodiazole and Glycine betaine treatments enhances phenolic compounds production in strawberry. Acta Horticulturae. 2002; 567: 353-356.

27. Lixin Zhang, Mei Gao, Linsen Zhang, Binzhi Li, Mingyu Han, Ashok Kumar Alva, Muhammad Ahsraf. Role of exogenous glycinebetaine and humic acid in mitigating drought stress-induced adverse effects in Malus robusta seedlings. Turkish Journal of Botany.2013; 37: 9280-929.

28. Chaluvaraju G, Basavaraju P, Shetty NP, Deepak SA, Amruthesh $\mathrm{KN}$, Shetty HS. Effect of some phosphorous-based compounds on control of pearl millet downy mildew disease. Crop Protection. 2004; 23: 595-600.
29. Amruthesh KN, Geetha NP, Lyngs Jorgensen HJ, de Neergard E, Shekar Shetty H. Unsaturated fatty acids from zoospores of Sclerospora graminicola induce resistance in Pearl millet. European Journal of Plant Pathology. 2005; 111: 125-137.

30. Girijamba R, Hariprasad P, Brijesh Singh S, Niranjana SR. AntiMildew activity of methanolic extract from selected medicinal plants against Plasmopara halstedii (Farl.) Berl. and De Toni incitant of Sunflower Downy mildew disease. International Journal of Pharma and Bio Sciences. 2014; 5(4): 1010-1019.

31. Geetha HM, Shetty HS. Induction of resistance in pearl millet against downy mildew disease caused by Sclerospora graminicola using benzathiadazole, calcium chloride and hydrogen peroxide- a comparative evaluation. Crop Protection. 2002; 21: 601-610.

32. Sharath Chandra RG, NiranjanRaj S, Shetty NP, Amruthesh KN, Shekar Shetty H. A chitosan formulation Elexa ${ }^{\mathrm{TM}}$ induces downy mildew disease resistance and growth promotion in Pearl millet. Crop Protection. 2004; 23: 881-888.

33. NiranjanRaj S, Shetty NP, Shetty HS. Proline-An Inducer of Resistance against Pearl Millet Downy Mildew Disease Caused by Sclerospora graminicola. Phytoparasitica. 2004; 32(5): 523-527.

34. Park EJ, Jeknic Z, Chen THH. Exogenous application of glycinebetaine increases chilling tolerance in tomato plants. Plant Cell Physiology. 2006; 47(6): 706-714.

35. Makela P, Jokinen K, Kontturi M, Peltonen-Sainio P, Pehu E \& Somersalo $S$ Foliar application of glycine betaine - a novel product from sugar beet as an approach to increase tomato yield. Industrial Crops and Products. 1998; 7: 139-148.

36. Parviz Malekzadeh. Influence of exogenous application of glycinebetaine on antioxidative system and growth of salt-stressed soybean seedlings (Glycine max L.). Physiology and Molecular Biology of Plants. 2015; 21(2): 225-23.

37. Karabudak T, Bor M, zdemir FO ,Turkan. Glycine betaine protects tomato (Solanum lycopersicum) plants at low temperature by inducing fatty acid desaturase7 and lipoxygenase gene expression, Molecular Biology Reports. 2014; 41: 1401-1410.

\section{How to cite this article:}

Lavanya NS, Amruthesh NK. Glycine betaine mediated disease resistance against Sclerospora graminicola in Pearl Millet. J App Biol Biotech. 2017; 5 (03): 045-051. DOI: 10.7324/JABB.2017.50308 